\title{
Editorial
}

\section{BNCC, Reforma do Ensino Médio e BNC-Formação: um pacote privatista, utilitarista minimalista que precisa ser revogado}

O debate sobre o lugar da disciplina de Física no currículo do ensino médio frente às políticas curriculares dos últimos anos, levantado por Ostermann (2020), requer um olhar mais amplo e crítico que pense politicamente a educação no Brasil, como abordado em editorial anterior (SELLES, 2018). Nessa perspectiva, a educação e o currículo podem ser compreendidos como um campo de disputas de projetos defendidos por diferentes atores políticos envolvidos no debate (AGUIAR; TUTTMAN, 2020). A posição neoliberal, mais alinhada às demandas do mercado e que minimiza o papel do Estado frente às políticas públicas de educação, e a posição crítica, que considera a educação como direito de todos a ser assegurado pelo Estado, têm sido, grosso modo, as duas posições em confronto.

Alinhada à agenda global dos organismos internacionais (tais como a Organização do Comércio e Desenvolvimento Econômico - OCDE, o Banco Mundial e a UNESCO), a posição neoliberal concebe a educação enquanto força produtiva, um elemento chave para o desenvolvimento do capitalismo na sua etapa de financeirização. Responsiva às demandas do mercado, busca minimizar o papel do Estado frente às políticas públicas de educação, priorizando a formação de força de trabalho e favorecendo o gerencialismo, o estabelecimento de competências e a cultura da performatividade. Os protagonistas nesse lado do debate educacional são os reformadores empresariais (FREITAS, 2012), uma coalizão entre políticos, mídia, empresários, empresas educacionais, institutos e fundações privadas e pesquisadores alinhados com a ideia de que a iniciativa privada tem uma proposta mais adequada para "consertar" a educação. A qualidade da educação é colocada sob responsabilização do professor e expectativas de aprendizagem são defendidas na perspectiva de um conjunto de obrigações imputadas somente aos estudantes, para a consolidação das tarefas e avaliações. Em um contexto de permanente culpabilização destes, a responsabilidade pelos resultados escolares passa a ser de suas famílias e de seu contexto sociocultural.

Por outro lado, a posição crítica, que vamos tentar enunciar por meio do nosso posicionamento e o de alguns autores, defende mudanças sociais e econômicas profundas em prol de uma sociedade justa, considerando a educação de qualidade como direito de todos a ser assegurado pelo Estado no contexto de um país com extrema desigualdade social como o Brasil. A defesa do direito à educação enseja o debate acerca das condições por meio das quais o Estado brasileiro tem garantido, ou não, as possibilidades para que as tarefas, finalidades e resultados escolares sejam efetivados de modo positivo na vida dos estudantes no cotidiano da instituição escolar. A qualidade da educação não é considerada apenas 
responsabilidade do professor; ao contrário, será reconhecida como dependente de um conjunto de fatores onde pesam: os investimentos públicos, o financiamento público, as condições objetivas, a situação socioeconômica cultural das famílias. Educadores profissionais são os atores à frente da defesa dessa posição, que aposta na transformação social, visando ao desenvolvimento da solidariedade entre as pessoas, a valorização da autoorganização dos estudantes e do trabalho coletivo, bem como o respeito à diversidade cultural (AGUIAR; TUTTMAN, 2020).

No Governo Fernando Henrique Cardoso (1994-2002), foi aprovada nova LDB (1996) e se buscou implementar políticas educacionais alinhadas à posição neoliberal como os PCN e o ENEM. O governo Lula (2003-2010) dá continuidade às políticas educacionais do governo FHC. Entretanto, pautas da comunidade educacional foram atendidas, como o financiamento para a educação básica, uma preocupação com a valorização do professor e a extensão do ensino fundamental com nove anos.

No Governo Dilma (2011-2016), foi elaborado um documento visando a uma contribuição crítica ao debate sobre uma base nacional comum curricular numa perspectiva não mais fundamentada na pedagogia das competências. No entanto, a nomeação, em 2015, de um reformador empresarial para ministro da Educação e o protagonismo do Movimento pela Base (Fundação Lemann) significarão uma guinada em direção à posição neoliberal, que marcarão a $1^{\mathrm{a}}$ versão de uma Proposta da Base Nacional Comum Curricular (BNCC). Várias associações, como ANPED e ABRAPEC, colocaram-se contra a BNCC, denunciando tal política como um currículo prescritivo que respondia às tendências internacionais de uniformização e centralização curricular, avaliações padronizadas e de responsabilização de professores e gestores. Em 2016, após um período de críticas e sugestões, a $2^{\mathrm{a}}$ versão da BNCC foi elaborada pelo MEC.

Após o golpe de 2016, com a ascensão do Governo Michel Temer, políticas educacionais foram redirecionadas, programas foram interrompidos, bem como foram esvaziados e modificados vários conselhos, como o Conselho Nacional de Educação. A composição do Fórum Nacional de Educação e a organização das Conferências Nacionais de Educação também foram alteradas, num movimento claro de ameaça à democracia e de uma guinada mais acentuada à posição neoliberal. Em contrapartida, como forma de resistência, foi criado, em 2017, o Fórum Nacional Popular de Educação e a Conferência Nacional Popular de Educação, em 2018. Com a nomeação de M. H. G. de Castro, secretária-executiva do MEC do governo FHC, são realizados seminários sobre a $2^{\mathrm{a}}$ versão da $\mathrm{BNCC}$, organizados pelo Conselho Nacional de Secretários de Educação e a União dos Dirigentes Municipais de Educação.

A $3^{\mathrm{a}}$ versão da $\mathrm{BNCC}$, referente à Educação Infantil e Ensino Fundamental (BRASIL, 2017a), elaborada pelo Comitê Gestor do MEC em 2017, foi também alvo de intensas críticas das associações científicas, como a ANPAE, ANPED, ANFOPE e ABRAPEC. Ainda assim, o documento foi aprovado neste mesmo ano. A BNCC do Ensino 
Médio (BNCC-EM), também tendo sofrido inúmeras críticas das associações, dos professores e dos estudantes, foi aprovada pelo Conselho Nacional de Educação em 2018. Uma das principais críticas a esse documento refere-se à sua racionalidade utilitarista, imposta pela lógica das competências, que segue os moldes das avaliações internacionais da OCDE, como o PISA. Essa lógica afasta-se de qualquer forma de explicação sobre o que dá sentido à história da sociedade, à vida social ou à história da ciência (LEHER, 2021). Sua racionalidade utilitarista é guiada pela teoria do capital humano, segundo a qual a escola forma recursos humanos e não cidadãos, o que significa submissão da educação ao mundo produtivo.

$\mathrm{Na}$ área de Ciências da Natureza e suas Tecnologias, em particular, percebe-se o reducionismo conceitual, tanto pelo número exíguo de temáticas, quanto pela superficialidade com que são abordadas no documento. A identificação das habilidades por códigos alfanuméricos permite sua relação direta com os conteúdos do Exame Nacional do Ensino Médio, o que indica o empobrecimento dos objetivos da educação científica, por meio de sua limitação ao que é cobrado nesse exame.

De forma coesa com a BNCC-EM (BRASIL, 2018), a Lei da Reforma do Ensino médio (BRASIL, 2017b) altera a Lei de Diretrizes e Bases da Educação Nacional de 1996, ampliando o tempo deste nível escolar de 800 para 1000 horas anuais, embora reforce ainda mais o aspecto profissionalizante da formação dos jovens. A formação secundária foi dividida em duas etapas: a primeira, voltada à formação geral (até 1800 h) e a segunda, com carga horária de $1200 \mathrm{~h}$, realizada por meio de itinerários formativos. Nessa etapa, o sistema pode oferecer cinco itinerários: quatro que correspondem às áreas de conhecimento do ensino médio (Matemáticas e suas Tecnologias, Linguagens e suas Tecnologias, Ciências da Natureza e suas Tecnologias e Ciências Humanas e Sociais Aplicadas) e um itinerário direcionado à formação técnica e profissional. Ao percorrerem os diferentes itinerários, os estudantes podem se aprofundar em uma ou mais áreas de conhecimento e também em conteúdos relativos à formação profissional.

Entretanto, por lei, as escolas não são obrigadas a oferecer os cinco itinerários formativos, devendo obrigatoriamente oferecer apenas um, cenário que representaria o total empobrecimento da formação de nível médio. Além disso, segundo a legislação, as opções "deverão ser organizadas por meio da oferta de diferentes arranjos curriculares" (BRASIL, 2017b), o que pode significar uma heterogeneidade ampliada da formação, e que segundo Frigotto (2021), liquidaria o direito universal à formação básica de mesma qualidade para os jovens. $\mathrm{O}$ autor considera que, dados o atual sucateamento das escolas públicas e a possibilidade que a lei faculta de parcerias com o setor privado, o "arranjo" proposto na legislação poderá se dar pelo itinerário da formação profissional, o que já vem se concretizando no Estado do Rio de Janeiro.

A divisão do currículo do ensino médio em duas etapas pela recente reforma, sendo uma delas construída de acordo com preferências do estudante, tem forte influência do currículo estadunidense. Segundo a legislação, a mudança teria como um de seus objetivos 
aproximar as escolas à realidade dos estudantes de hoje, considerando as novas demandas e complexidades do mundo do trabalho e da vida em sociedade, revisitando, assim, finalidades voltadas à lógica do mercado (OSTERMANN; REZENDE, 2020). No momento atual, as redes de ensino estão se adaptando a essa nova legislação, com autonomia para definir quais os itinerários formativos ofertarão. Dada a falta de professores em áreas como ciências da Natureza as escolas públicas poderão ficar restritas ao itinerário técnico e profissional, que exige dos profissionais não docentes, apenas 'notório saber'. Considerando que mais de $80 \%$ dos alunos do ensino médio no Brasil estudam em escolas públicas, a consequência clara dessa reforma é que a todos estes jovens restará apenas a formação profissional. Assim, a reforma condena a geração de jovens "a não terem as ferramentas básicas de conhecimento para a cidadania política e econômica" (FRIGOTTO, 2021).

Outro problema da reforma proposta é a ideia de que, por ser dirigida apenas ao ensino médio, acaba por enfraquecer a organicidade da educação básica, atribuída pela LDB de 1996 à formação geral desenvolvida desde a educação infantil ao ensino médio (AGUIAR; TUTTMAN, 2020). Tal ressignificação do currículo representa, para os sujeitos, um retrocesso cultural, na medida em que fragmenta e subtrai sua formação geral. Frigotto (2021) usa a expressão de "pastel de vento" para o sentido que passa ter a educação básica com essa reforma, mostrando também que ao não oferecer o conhecimento básico, há apenas "o vento" a ser instrumentalizado.

Tomando a BNCC por referência, foram elaboradas, em 2019, as Diretrizes Curriculares Nacionais para a Formação Inicial de Professores para a Educação Básica (DCNFP 2019) (BRASIL, 2019), que passam a integrar um sistema de políticas públicas educacionais engendrado com interdependência, alinhamento e padronização.

As DCN-FP 2019 revogaram as Diretrizes Curriculares Nacionais para a Formação Inicial em Nível Superior e para a Formação Continuada (DCN-FP 2015) (BRASIL, 2015), consideradas pela comunidade acadêmica como elaboração conceitual alinhada a uma perspectiva crítica de formação. Em contraste, via um processo autoritário, as DCN-FP 2019 foram elaboradas por seis autores, sendo cinco reformadores empresariais. Na época, um manifesto em protesto contra essa legislação - e à descaracterização da formação docente que essa lei impõe - e em defesa da DCN-FP 2015, foi assinado por mais de 30 associações científicas.

Ao reduzir a formação do professor às competências gerais estabelecidas pela BNCC e BNCC-EM, as DCN-FP 2019 instituem uma inaceitável equiparação entre as competências gerais requeridas dos estudantes e o que é esperado do licenciando. Os objetos do conhecimento da BNCC são tomados como referência tanto para a formação quanto para a prática pedagógica do professor, ocupando metade da carga horária total da formação. As competências docentes propostas referem-se a três dimensões fundamentais: conhecimento profissional, prática profissional e engajamento profissional. Tais dimensões, restritas à escola, deixam de fora a complexidade do ensinar, a diversidade dos contextos de trabalho e a 
pluralidade social dos estudantes. A prática profissional, especificamente, compõe-se pelas seguintes ações: (i) planejar as ações de ensino que resultem em efetivas aprendizagens; (ii) criar e saber gerir os ambientes de aprendizagem; (iii) avaliar o desenvolvimento do educando, a aprendizagem e o ensino; e (iv) conduzir as práticas pedagógicas dos objetos do conhecimento, as competências e as habilidades. Esses tipos de ação ficam restritas à tríade ensino-aprendizagem-avaliação, sem espaço para qualquer outra atividade que entenda o professor como um intelectual. A apropriação da expressão "engajamento profissional" dos ambientes corporativos (DAL'IGNA et al., 2019) claramente expele da profissão docente qualquer compromisso de caráter emancipatório e transformador da realidade social.

Procurando dar um fechamento à discussão das políticas curriculares, embora esteja claro que seria impossível dar conta de todos os pontos levantados, trazemos nesses parágrafos finais, ideias mais amplas, que circundam o debate. Entendemos que a educação pública praticada a partir do pacote de políticas (BNCC, BNCC-EM e as DCN-FP 2019) apresenta consistente caráter utilitarista minimalista (LEHER, 2021), que aligeira, subtrai, reduz a formação dos jovens e dos professores ao mínimo de complexidade, necessário ao projeto neoliberal de "empreendedorismo popular" ou de "plataformização do trabalho". Nesse contexto, o lugar da Física no currículo do ensino médio, assim como o de outras disciplinas, está seriamente ameaçado. Assim como está seriamente comprometido o currículo da formação docente estabelecida pelas DCN-FP 2019 por meio da correspondência entre as competências dos professores e as dos alunos da educação básica.

Esse conjunto de leis instituídas desde o governo Temer, que dão face a um estado de neoliberalismo extremo, tem continuidade no atual governo, com a concordância da alta burguesia, que acabou também tendo que aceitar sua guerra cultural, bandeira da extrema direita. A perspectiva é do desmanche de tudo que é público como consta na Constituição de 1988. A agenda "educacional" do governo é, então, converter a educação em uma área de negócios, sem a concorrência "desleal" da educação pública. O processo reformista se soma à guerra cultural, que tem como entendimento a ideia de que a ciência é uma ficção verbal, convertendo-se assim numa opinião (LEHER, 2021). A partir dessa visão, não há como distinguir entre verdadeiro e falso. Tais concepções são ataques frontais a qualquer processo de ensino-aprendizagem no contexto da educação científica.

De um ponto de vista crítico, por tudo que esse pacote de políticas curriculares representa e pelo modo como se materializa, não vemos outra reação à altura da gravidade da situação, se não a de exigir sua revogação. A partir daí, precisamos, segundo Leher (2021), de um novo ponto de partida: um discurso e uma agenda política para a educação pública que possam ser defendidos por pais, professores e estudantes, e que, segundo o autor, também precisam ser apaixonantes. 


\section{Referências}

AGUIAR, M. A.; TUTTMAN, M. T. Políticas educacionais no Brasil e a Base Nacional Comum Curricular: disputas de projetos. Em Aberto, Brasília, v. 33, n. 107, p. 69-94, jan./abr. 2020. Disponível em:

$<$ http://emaberto.inep.gov.br/ojs3/index.php/emaberto/article/view/4556>. Acesso em: jul. 2021.

BRASIL. Ministério da Educação. Base Nacional Comum Curricular: Educação Infantil e Ensino Fundamental. Brasília, 2017a. Disponível em:

$<$ http://basenacionalcomum.mec.gov.br/abase>. Acesso em: nov. 2021.

BRASIL. Lei $\mathbf{n}^{\mathbf{0}}$ 13.415, de 16 de fevereiro de 2017. Reforma do Ensino Médio. Brasília. 2017b. Disponível em: <https://www.planalto.gov.br/ccivil_03/_Ato2015-2018/2017/Lei/ L13415.htm>. Acesso em: nov. 2021.

BRASIL. Ministério da Educação. Base Nacional Comum Curricular: Ensino Médio. Brasília, 2018. Disponível em: <http://basenacionalcomum.mec.gov.br/abase/\#medio>. Acesso em: nov. 2021.

BRASIL. Ministério da Educação. Resolução CNE/CP No 2, de 20 de dezembro de 2019. Brasília, 2019. Disponível em: <http://portal.mec.gov.br/docman/dezembro-2019-pdf/ 135951-rcp002-19/file>. Acesso em: nov. 2021.

FREITAS, L. C. de. Os reformadores empresariais da Educação: da desmoralização do magistério à destruição do sistema público de educação. Educação \& Sociedade, Campinas, v. 33, n. 119, p. 379-404, 2012.

FRIGOTTO, G. O "novo ensino médio": traição à juventude que frequenta a escola pública. Brasil de Fato | Rio de Janeiro (RJ) | 05 de Novembro de 2021. Disponível em: $<$ https:/www.brasildefato.com.br/2021/11/05/analise-o-novo-ensino-medio-traicao-ajuventude-que-frequenta-a-escola-publica>. Acesso em: 05 nov. 2021.

LEHER, R. Apresentação na mesa redonda Legitimação dos saberes e políticas de docência frente aos movimentos neoconservadores e ao retrocesso democrático. In: ENCONTRO NACIONAL DE PESQUISA EM EDUCAÇÃO EM CIÊNCIAS, XIII, 2021. Disponível em: $<$ https://youtu.be/tXSVajBhZyE>. Acesso em: 01 out. 2021.

OSTERMANN, F.; REZENDE, F. Uma interpretação da educação em ciências no Brasil a partir da perspectiva do currículo como prática cultural. Investigação e Práticas em 
Educação em Ciências, Matemática e Tecnologia, Vila Real, Portugal, v. 1, n. 1, p. 30-40, 2020.

OSTERMANN, F. Apresentação na mesa redonda Formação docente em tempos de BNCC e das Novas Diretrizes Curriculares para o Ensino Médio. In: ENCONTRO NACIONAL DE PESQUISA EM ENSINO DE FÍSICA, XVIII, 2020.

SELLES, S.E. A BNCC e a Resolução CNE/CP no 2/2015 para a formação docente: a "carroça na frente dos bois". Caderno Brasileiro de Ensino de Física, v. 35, n. 2, p. 337 $344,2018$.

\section{Fernanda Ostermann \\ Flavia Rezende ${ }^{l}$}

Programa de Pós-Graduação em Ensino de Física

Universidade Federal do Rio Grande do Sul

\footnotetext{
${ }^{1}$ E-mails: fernanda.ostermann@ufrgs.br; flaviarezende@uol.com.br
} 